\title{
TO STUDY THE ULCEROPROTECTIVE EFFECT OF LEAVES OF MORINGA OLEIFERA ON EXPERIMENTALLY INDUCED INFLAMMATORY BOWEL DISEASE ON ANIMAL MODELS
}

\author{
SHIPRA KAUSHIK ${ }^{*}$, SHOBHIT KAUSHIK ${ }^{2}$ \\ ${ }^{1}$ Department of Pharmacology, GS Medical College and Hospital, Pilkhuwa, Hapur, Uttar Pradesh, India. ${ }^{2}$ Department of Anaesthesiology, \\ Assam Medical College and Hospital, Dibrugarh, Assam, India. Email: shipra014@gmail.com
}

Received: 21 May 2019, Revised and Accepted: 18 June 2019

\section{ABSTRACT}

Objective: The present study was carried out to evaluate the ulceroprotective effect of ethanolic extract of leaves of Moringa oleifera (EEMO) on experimentally induced inflammatory bowel disease (IBD) on Albino (Wistar strain) rats.

Methods: The rats were divided into four groups of six animals each. Group A and Group B received gum acacia per orally (P.O.), Group C received EEMO in dose of $500 \mathrm{mg} / \mathrm{kg} /$ day P.O., and Group D received 5-aminosalicylic acid (5-ASA) in the dose of $100 \mathrm{mg} / \mathrm{kg} /$ day P.O. All the animals were pre-treated with respective drugs (volume of drugs was kept constant at $10 \mathrm{ml} / \mathrm{kg}$ ) for 5 days, along with the normal diet. On $5^{\text {th }}$ day, animals were kept fasting for $12 \mathrm{~h}$ (overnight), and IBD was induced next morning in Groups B, C, and D by the administration of $1 \mathrm{ml}$ of $4 \%$ acetic acid solution transrectally (TR). Group A (normal control) received 0.9\% normal saline TR instead.

Results: The results have been shown that EEMO has significant activity against experimentally induced IBD when compared to the experimental control, with near normalization of colon architecture both macroscopically as well as microscopically. Tissue oxidative stress was reduced with significant improvement in tissue levels of superoxide dismutase (SOD) and catalase (CAT). Furthermore, significant improvement in levels of myeloperoxidase (MPO) was observed.

Conclusion: It is concluded that EEMO has got potent activity against experimentally induced IBD due to its anti-inflammatory and antioxidant properties.

Keywords: Anti-inflammatory, Moringa oleifera, Inflammatory bowel disease.

(c) 2019 The Authors. Published by Innovare Academic Sciences Pvt Ltd. This is an open access article under the CC BY license (http://creativecommons. org/licenses/by/4. 0/) DOI: http://dx.doi.org/10.22159/ajpcr.2019.v12i8.34227

\section{INTRODUCTION}

IBD is a disorder characterized by chronic inflammation of the gastrointestinal tract. There are two clinical subtypes: Ulcerative colitis (UC) and Crohn's disease (CD). UC is limited to the colon (large intestine), while $\mathrm{CD}$ can involve any part of the gastrointestinal tract from mouth to anus, and it most commonly affects the small intestine and/or the colon [1]. The IBD is associated with colon cancer [2].

Despite the fact that a number of theories have been proposed to describe the causative agent in IBD, still, the etiology of IBD remains unknown. Clinical, epidemiological, and experimental studies have been used to attempt to elucidate the etiology of IBD. A number of factors, including genetic, microbial, viral, immunological, nutritional, thrombosis, and environmental agents, have been implicated in the pathogenesis of IBD [3]. Neutrophil infiltration in the extravascular space involves a complex sequence of interaction between circulating neutrophils and the vascular endothelium, including rolling, adhesion, and transendothelial migration. MPO is an enzyme mainly found in azurophilic granules of neutrophils. It is a good marker of neutrophil infiltration in gastrointestinal tissues, as well as inflammation and tissue injury. Besides, significant amounts of superoxide can be generated by a variety of endogenous enzyme systems such as the peroxisomal enzyme xanthine oxidase (XO) following tissue ischemia. $\mathrm{XO}$ activity is often increased in intestinal inflammation through the induction by tumor necrosis factor-alpha and activated neutrophils [4]. It has been suggested that XO is a significant source of superoxide in the inflammation of IBD [5]. The concentrations of endogenous antioxidants such as reduced glutathione, alpha-tocopherol, and cysteine are all significantly decreased in IBD patients. As a result, the balance between antioxidants and reactive oxygen metabolites becomes seriously impaired [6]. A population-based study performed in
India for UC shows a prevalence rate of 44.3/100,000 inhabitants and an incidence rate of 6.02 cases $/ 100,000$ inhabitants [7].

The evaluation of various plant products according to their traditional uses and medicinal value based on their therapeutic efficacy leads to the discovery of newer and recent drugs for treating various ailments. This fact forms the basis for the development of new drugs from various plant sources. One of such plants of medicinal value is M. oleifera [8].

M. oleifera Lam. (Drumstick tree) a plant in a family of Moringaceae is widely cultivated in India, used as food and active ingredient of the food preparation, medication, and oil manufacturing. Almost, all parts of the plant have been utilized in traditional medical practices. It is believed to be a miracle herb because it can be used as food as well as medicine for numerous ailments. The leaves and young buds of the plant are used as a vegetable and can be rubbed on the temples for relieving headache, while the root and root bark are regarded as antiscorbutic and can be externally used as counter-irritants. The juice of leaves mixed with honey is used for the treatment of eye diseases. The leaves of the plants have also been reported or its antitumor, hypotensive, antioxidant, radioprotective, anti-inflammatory, and diuretic properties [9].

\section{METHODS}

This study has been approved by the IEAC, Assam Medical College, Dibrugarh, Certificate no. being AMC/EC/PG/2011/11517 dated 06/09/2011.

\section{Plant authentication}

Fresh tender leaves of $M$. oleifera approximately $1 \mathrm{~kg}$, collected in the year 2010, were used for the study. The plant was authenticated by 
Dr. M. Islam, Professor of Life Science, Dibrugarh University, Dibrugarh, Assam, India (Voucher No. 05).

\section{Preparation of plant extract}

An amount of $180 \mathrm{~g}$ of dried powder was obtained, and 95\% ethanol was added to the powdered drug in sufficient amount to render it evenly and distinctly damped. The entire solution was transferred to a percolator and to its sufficient amount of $95 \%$ of ethanol was added. The top of the percolator was closed, and when liquid was about to drip from the apparatus, the lower orifice of the percolator was also closed, and the solution was allowed to macerate for $24 \mathrm{~h}$ at room temperature. After $24 \mathrm{~h}$ of maceration, percolation was allowed slowly at the rate not exceeding $1 \mathrm{ml} / \mathrm{min}$ [10]. The residue thus obtained was collected in glass Petri dishes and allowed to evaporate at room temperature. When completely dried, the extract was scrapped out, weighed, and stored for further use. The yield at the end of extraction was $16 \mathrm{~g}$.

\section{Animals}

The study was conducted on male and female healthy Albino Wistar rats weighing 150-250 g. The animals were obtained from the Central Animal House, Assam Medical College, Dibrugarh. The rats were housed in polypropylene cages and maintained under standard conditions (12 h light/dark cycle, at room temperature $25^{\circ} \mathrm{C} \pm 3^{\circ} \mathrm{C}$ and $35 \%-60 \%$ humidity). The rats were maintained on standard animal diet of Bengal gram, wheat, maize and carrot in sufficient quantity for the entire period of the experiment. Water was given ad libitum during the entire period of the experiment. The study was approved by the Institutional Animal Ethics Committee, AMC. The albino rats were maintained and followed under the good laboratory practices and the guidelines of Committee for the Purpose of Control and Supervision on Experiments on Animals [11].

\section{Induction of experimental IBD}

For induction of IBD, a soft pediatric catheter was advanced $6 \mathrm{~cm}$ from the anus under low-dose ether anesthesia. Rats were in Trendelenburg position during this process, and $1 \mathrm{ml}$ of $4 \%$ acetic acid or $0.9 \% \mathrm{NS}$ solution was slowly administered TR. The rats were maintained in head-down position for $30 \mathrm{~s}$ to prevent leakage, and the rest of the solution was aspirated. After this process, $2 \mathrm{ml}$ of a phosphate buffer solution with $\mathrm{pH} 7$ was administered TR. All the animals were sacrificed after $48 \mathrm{~h}$ of IBD induction by ether overdose. The abdomen was opened and colon was exposed. Distal $8 \mathrm{~cm}$ of colon was excised and opened by a longitudinal incision. After washing the mucosa with saline solution, the mucosal injury was assessed macroscopically using scale of Morris et al. [12,13]. Disease activity index (DAI) was also measured, the ratio of colon weight to body weight, which was used as a parameter to assess the degree of tissue edema and reflects the severity of colonic inflammation. A 6-8 $\mathrm{mm}$ sample block of the inflamed colonic tissue with the full thickness was excised from a region of grossly visible damage for histological analysis. Formalin-fixed tissue samples were embedded in paraffin and stained with hematoxylin and eosin stain. Colonic tissues were scored for histological damage using the criteria of Wallace and Keenan. After scoring colonic tissue samples were homogenized with 10 volumes of ice-cold 0.25 M sucrose, centrifuged at $14,000 \mathrm{rpm}$ to measure the biochemical parameters in resulting supernatant [3].

\section{Biochemical assessments}

Myeloperoxidase (MPO) activity, superoxide dismutase (SOD) level, and Catalase (CAT) level. The above parameters were measured using double beam UV-spectrophotometer [14,15].

\section{Acute oral toxicity test in rats}

After overnight fasting of rats, EEMO was given orally in doses of 50, $100,200,500$, and maximum dose of $1000 \mathrm{mg} / \mathrm{kg}$ body weight and observed carefully for the first $2-3 \mathrm{~h}$ for signs of toxicity. The behavioral changes and percentage mortality were documented beginning with $24 \mathrm{~h}$ up to a period of 14 days [16].

\section{Experimental design}

Twenty four healthy Wistar albino rats weighing 150-200 g were used in the study and divided into four groups with six animals in each group as follows:

1. Group A (normal control) received $3 \%$ gum acacia $10 \mathrm{ml} / \mathrm{kg} / \mathrm{day}, \mathrm{P} . \mathrm{O}$.

2. GroupB (experimental control) received $3 \%$ gum acacia $10 \mathrm{ml} / \mathrm{kg} /$ day,P.O.

3. Group C (test) received EEMO $500 \mathrm{mg} / \mathrm{kg} /$ day, P.O.

4. Group D (standard) received 5-ASA acid $100 \mathrm{mg} / \mathrm{kg} /$ day, P.O.

All the animals were pre-treated with respective drugs (volume of drugs was kept constant at $10 \mathrm{ml} / \mathrm{kg}$ ) for 5 days, along with the normal diet. On $5^{\text {th }}$ day, animals were kept fasting for $12 \mathrm{~h}$ (overnight), and IBD was induced next morning in Groups B, C, and D by the administration of $1 \mathrm{ml}$ of $4 \%$ acetic acid solution TR. Group A (normal control) received $0.9 \%$ normal saline TR instead.

\section{Statistical analysis}

Data were calculated as the mean \pm standard error of mean (SEM). Statistical analysis was performed using SPSS (IBM SPSS Statistics Version 20.0). The values were analyzed using one-way analysis of variance (ANOVA), followed by post hoc Dunnett's multiple comparison tests. The results were considered to be significant when $\mathrm{p}<0.05$.

\section{RESULTS}

\section{Acute toxicity study}

Acute toxicity study showed that no signs of toxicity, behavioral changes, and mortality were there up to a dose of $1000 \mathrm{mg} / \mathrm{kg}$ body weight of the acute toxicity estimate.

\section{Effect on IBD-induced rats}

Normal control

Group A, normal control, showed normal mucosal architecture macroscopically and microscopically (Table 1, Figs. 1a and 2).

Table 1: Effect of Moringa oleifera (L) on experimentally induced inflammatory bowel disease

\begin{tabular}{lllllll}
\hline Groups & $\begin{array}{l}\text { Macroscopic } \\
\text { score }\end{array}$ & DAI & $\begin{array}{l}\text { Microscopic } \\
\text { score }\end{array}$ & $\begin{array}{l}\text { Tissue CAT } \\
(\boldsymbol{\mu m o l} / \mathbf{m i n} / \mathbf{m g} \text { of proteins) }\end{array}$ & $\begin{array}{l}\text { Tissue SOD (U/mg proteins) } \\
\text { of prome }\end{array}$ & $\begin{array}{l}\text { Tissue } \\
\text { MPO (U/g) }\end{array}$ \\
\hline A (normal control) & $0.33 \pm 0.21^{\mathrm{a}, \mathrm{d}}$ & $0.51 \pm 0.02^{\mathrm{a}, \mathrm{d}}$ & $0 \pm 0^{\mathrm{a}, \mathrm{c}}$ & $400.6 \pm 1.9^{\mathrm{a}, \mathrm{c}}$ & $6.9 \pm 0.33^{\mathrm{a}, \mathrm{c}}$ & $0.31 \pm 0.01^{\mathrm{a}, \mathrm{c}}$ \\
B (experimental control) & $4.6 \pm 0.25^{\mathrm{c}}$ & $1.8 \pm 0.02^{\mathrm{c}}$ & $4.8 \pm 0.20^{\mathrm{c}}$ & $148.3 \pm 0.33^{\mathrm{c}}$ & $3.4 \pm 0.24^{\mathrm{c}}$ & $3.8 \pm 0.04^{\mathrm{c}}$ \\
C (EEMO) & $3.2 \pm 0.20^{\mathrm{a}, \mathrm{c}}$ & $0.86 \pm 0.01^{\mathrm{a}, \mathrm{c}}$ & $0.55 \pm 0.24^{\mathrm{a}, \mathrm{c}}$ & $306.6 \pm 1.03^{\mathrm{a}, \mathrm{c}}$ & $5.2 \pm 0.32^{\mathrm{a}, \mathrm{c}}$ & $2.3 \pm 0.04^{\mathrm{a}, \mathrm{c}}$ \\
D (5-ASA) & $2.4 \pm 0.25^{\mathrm{a}}$ & $0.74 \pm 0.06^{\mathrm{a}}$ & $2.4 \pm 0.24^{\mathrm{a}}$ & $304.9 \pm 9.23^{\mathrm{a}}$ & $360.8 \pm 0.71^{\mathrm{a}}$ & $1.2 \pm 0.02^{\mathrm{a}}$ \\
$\mathrm{A}^{\mathrm{F}}$ & 50.26 & 28.29 & 70.37 & 250.8 & 28.44 & 333.4 \\
$\mathrm{~N}^{\mathrm{df}}$ & 20,3 & 20,3 & 20,3 & 20,3 & 20,3 & 20,3 \\
$0^{\mathrm{p}}$ & & & & $<0.05$ & $<0.05$
\end{tabular}

Values are expressed as mean \pm SEM, $n=6 .{ }^{a} \mathrm{p}<0.05$ and ${ }^{\mathrm{b}} \mathrm{p}>0.05$ when compared to experimental control; ${ }^{\mathrm{c}} \mathrm{p}<0.05$ and ${ }^{\mathrm{d}} \mathrm{p}>0.05$ when compared to 5 -ASA; ANOVA followed by Dunnett's t-test. DAI: Disease activity index, ANOVA: Analysis of variance, SEM: Standard error of mean, 5-ASA: 5-aminosalicylic acid, EEMO: Ethanolic extract of leaves of Moringa oleifera, CAT: Catalase, SOD: Superoxide dismutase, MPO: Myeloperoxidase 
Acetic acid

Acetic acid administration to the experimental control group caused significant macroscopic ulcerations and inflammations in the rat colon along with significant mucosal injury microscopically, when compared to the normal control group $(\mathrm{p}<0.05)$. Furthermore, there was a significant derangement of biochemical parameters including tissue levels of MPO, SOD, and CAT $(\mathrm{p}<0.05)$ showing oxidative stress due to colon damage and colonic inflammation (Table 1, Figs. 1b and 2).

\section{EEMO}

EEMO showed significant activity against experimentally induced IBD when compared to the experimental control $(\mathrm{p}<0.05)$ with near normalization of colon architecture both macroscopically and microscopically. Tissue oxidative stress was reduced with significant improvement in tissue levels of SOD and CAT $(\mathrm{p}<0.05)$. Furthermore, significant improvement in levels of MPO was observed $(p<0.05)$ (Table 1, Figs. 1c and 2).

5-ASA

As for the standard drug 5-ASA, its activity against IBD was significantly greater than EEMO with regard to all parameters $(p<0.05)$. When compared to the normal control, 5-ASA showed near normalization of DAI and macroscopic score, as there was no significant difference between normal control group and 5-ASA group ( $p>0.05$ ) (Table 1, Figs. 1d and 2).
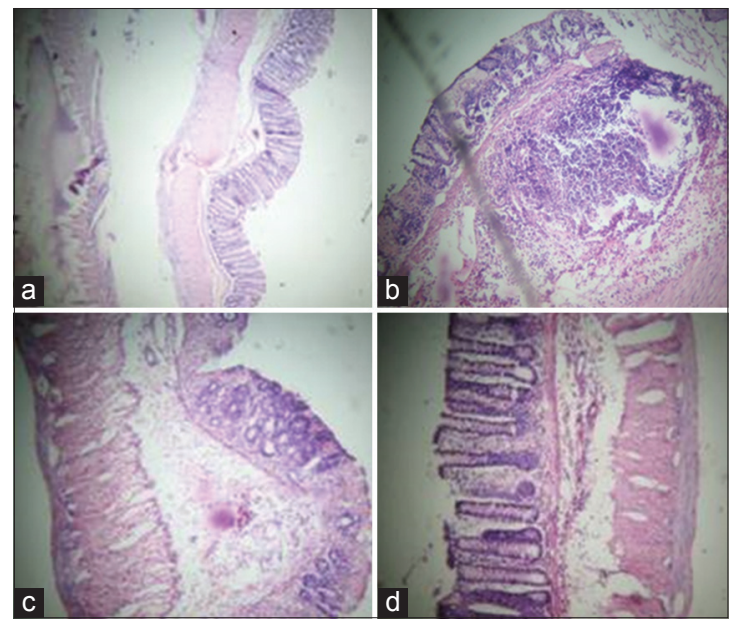

Fig. 1: Effect of Moringa oleifera (L) on experimentally induced IBD. (a) Normal control (Normal mucosal architecture). (b) Experimental control (Extensive necrosis and transmural infiltration). (c) Test (Infiltration up to submucosa, architecture maintained). (d) 5-ASA (Near normalization of architecture with mucosal infiltration only)

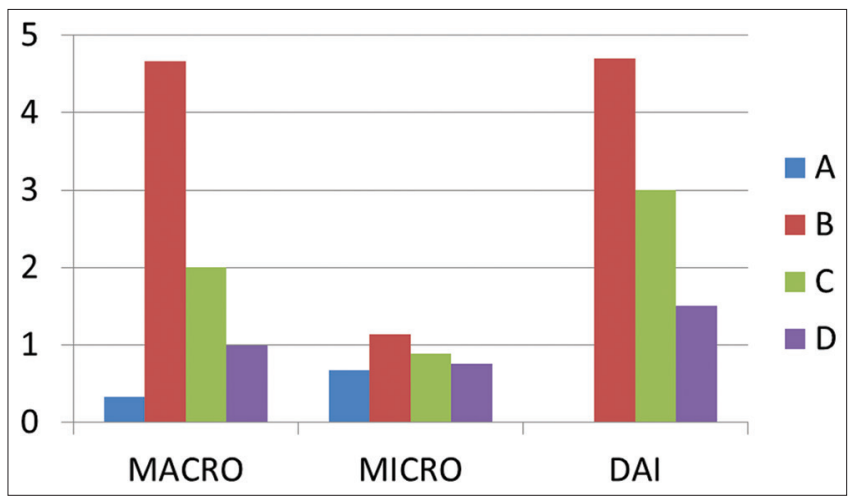

Fig. 2: Bar diagram showing macroscopic, microscopic, and disease activity index of the four Groups A, B, C, and D

\section{DISCUSSION}

The results showed that EEMO has got a good potential to suppress experimental colitis in rats, as indicated by macroscopic, microscopic, and biochemical evaluations.

Colitis is a term used to describe inflammation of the colon, which leads to various changes in the colonic histological organization [17].

Acetic acid-induced colitis model is similar to human UC in terms of histological features. It affects the distal colon portion and induces nontransmural inflammation, massive necrosis of mucosal and submucosal layers, mucosal edema, and neutrophil infiltration of the mucosa and submucosal ulceration. The protonated form of the acid liberates protons within the intracellular space and causes massive intracellular acidification resulting in massive epithelial damage. Inflammation is the pathogenesis of IBD and several pathways are associated with inflammatory response in IBD. The inflammatory response initiated by acetic acid includes activation of cyclooxygenase and lipoxygenase pathways [18].

Oxidative stress is believed to play a key role in the pathogenesis of IBD-related intestinal damage. As a matter of fact, intestinal mucosal damage in the IBD, including CD and UC, is related to both increased free radical production and to a low concentration of endogenous antioxidant defense [19].

As proved by the above study and also described in literature, leaves extract of $M$. oleifera possesses significant anti-oxidant property, proving its role in the management of experimentally induced IBD.

\section{CONCLUSION}

It can be concluded from the study that ethanol extract of leaves of M. oleifera has got potent activity against experimentally induced IBD due to its anti-inflammatory and antioxidant properties; still, it is to be further investigated for its clinical utility.

\section{AUTHORS' CONTRIBUTIONS}

Dr. Shipra Kaushik contributed in the drafting of protocol, conducting the experiment, collection, and analysis of data, drafting of the manuscript. Both the authors read and approve the final manuscript.

\section{CONFLICTS OF INTEREST}

Nil.

\section{REFERENCES}

1. Datt N, Patyar RR, Patyar S. Comparative evaluation of different doses of vinpocetine alone and in combination with sulfasalazine in experimentally induced inflammatory bowel disease in rats. Asian J Pharm Clin Res 2017;10:88-93.

2. Pengkumsri N, Suwannalert P, Sivamaruthi BS, Wongpoomchai R, Sirisattha S, Tammasakchai A, et al. Molecular, histological, and antioxidant evaluation of colitis induction in rats by different concentration of dextran sodium sulfate (5 kda). Int J Pharm Pharm Sci 2015;7:283-7. Available from: https://www.innovareacademics.in/journals/index.php/ ijpps/article/view/9356.

3. Gottfried IS, Nash HR, Devlin EW. Presence of novel forms in the colon of inflammatory bowel disease patients. Am J Gastroenterol 1999;94:537-9.

4. Ko JK, Lam FY, Cheung AP. Amelioration of experimental colitis by Astragalus membranaceus through anti-oxidation and inhibition of adhesion molecule synthesis. World J Gastroenterol 2005;11:5787-94.

5. Simmonds NJ, Rampton DS. Inflammatory bowel disease a radical view. Gut 1993;34:865-8.

6. Ramakrishna BS, Varghese R, Jayakumar S, Mathan M, Balasubramanian KA. Circulating antioxidants in ulcerative colitis and their relationship to disease severity and activity. J Gastroenterol Hepatol 1997;12:490-4.

7. Sood A, Midha V, Sood N, Bhatia AS, Avasthi G. Incidence and prevalence of ulcerative colitis in Punjab, North India. Gut 2003;52:1587-90. 
8. Mishra G, Singh P, Verma R, Kumar S, Srivastavi S, Jha K, et al. Traditional uses, phytochemistry and pharmacological properties of Moringa oleifera plant; an Overview. Der Pharm Lett 2011;3:141-64.

9. Fatima N, Fatima SJ. Pharmacological screening for anti-arthritic activity of Moringa oleifera. Asian J Pharm Clin Res 2016;9:106-11.

10. Remengton. Solution, Emulsion, Suspension and Extracts. The Science and Practice of Pharmacology. 19 ${ }^{\text {th }}$ ed. Pennsylvania: Mach Publishing Company; 1995. p. 1495-523.

11. CPCSEA (Committee for the Purpose of Control and Supervision on Experiments on Animals). CPCSEA guidelines for laboratory animal facility. Indian J Pharmacol 2003;35:257-74.

12. Zeytunlu M, Korkut M, Akgün E, Firat O, Aynaci M, Içöz G, et al. The comparative effects of calcium channel blockers in an experimental colitis model in rats. Turk J Gastroenterol 2004;15:243-9.

13. Morris GP, Beck PL, Herridge MS, Depew WT, Szewczuk MR, Wallace JL, et al. Hapten-induced model of chronic inflammation and ulceration in the rat colon. Gastroenterology 1989;96:795-803.
14. BEERS RF Jr., SIZER IW. A spectrophotometric method for measuring the breakdown of hydrogen peroxide by catalase. J Biol Chem 1952;195:133-40.

15. Krawisz JE, Sharon P, Stenson WF. Quantitative assay for acute intestinal inflammation based on myeloperoxidase activity. Assessment of inflammation in rat and hamster models. Gastroenterology 1984;87:1344-50

16. OECD/OCDE. 425 Guideline. OECD Guidelines for Testing of Chemicals. Acute Oral Toxicity Up-and-Down-Procedure; 2005. p. 1-26.

17. Souad L, Dalila N, Cherifa A. Hyperhomocysteinemia lead to transmural inflammation of colon and increase severity of disease in acetic acid-induced colitis in rat. Int J Pharm Pharm Sci 2017;9:108-16.

18. Dutta S, Das S. Effects of the leaves of Moringa oleifera in experimentally induced colitis in animal models. IJGP 2011;5:55-60.

19. Kanodia L, Borgohain M, Das S. Effect of fruit extract of Fragaria vesca L. On experimentally induced inflammatory bowel disease in albino rats. Indian J Pharmacol 2011;43:18-21. 